\title{
A Case Study of Risk Analysis due to Lightning for Wind Power Plants
}

\author{
R.B. Rodrigues ${ }^{1}$, V.M.F. Mendes ${ }^{1}$ and J.P.S. Catalão ${ }^{2}$ \\ ${ }^{1}$ Instituto Superior de Engenharia de Lisboa \\ Lisbon, Portugal \\ e-mail: rbrodrigues@deea.isel.ipl.pt, vfmendes@isel.pt \\ ${ }^{2}$ University of Beira Interior \\ Covilhã, Portugal \\ e-mail: catalao@ubi.pt
}

\begin{abstract}
This paper briefly describes the Portuguese Lightning Location System, and presents an overview of wind energy in Portugal. The method for risk assessment due to lightning flashes to earth, proposed by the International Electrotechnical Commission, IEC, is used. A wind power plant is characterized for a case study, and the standard IEC 62305-2 is applied. Results obtained are able to support the advantage for investors to take into account the lighting activity in the region where the wind power plant shall be installed. Also, the use of a well established risk assessment method allows the adoption of adequate protection measures.
\end{abstract}

\section{Key words}

Wind energy systems, lightning protection, lightning location system, risk analysis.

\section{Introduction}

The escalating number of wind turbine power plants in many countries makes their reliability an increasing problem. Particularly, in Portugal the first wind turbine with $20 \mathrm{~kW}$ was installed in 1985, but in September of 2007 the total capacity in operation reached 2037 MW and continues growing.

One of the main causes of damage on wind turbines is lightning [1]. Areas of favourable location for wind turbines often coincide with areas of lightning activity. Hence, it is expected that the increasing number of wind turbines and the increasing height of the towers installed will result in an incidence of lightning damages greater than anticipated with significant repair costs.

The influence of lightning faults on operational reliability becomes a concern as the capacity of individual wind turbines increases. In a study completed in 2002 [2] it is expected that up to 8 out of 100 wind turbines could be damaged by one direct lightning strike every year. Between 1992 and 1995 Germany alone reported 393 accidents with damages due to lightning: 124 direct strikes to the turbine, and the remainder through the electrical distribution network [3].
Direct and indirect effects of lightning can produce severe damages on electrical and mechanical components of wind turbines, being responsible for considerable unplanned downtime. The question is not "if" but "when" the wind turbine will be stroked.

Lightning is formed as a result of a natural build-up of electrical charge separation in storm clouds. How clouds form is well understood. How the cloud separates its charge is not. Many theories have been put forward but everyone seems to agree that in a thunder-cloud, ice crystals become positively charged while water droplets carry a negative charge. When the voltage difference between the cloud base and the ground or a structure on the ground becomes so great that it causes a breakdown of the air's resistance, we have a lightning discharge. The most common lightning in what regards to wind turbine lightning protection, is cloud-to-ground (CG) lightning [4].

Wind turbines typically have two or three blades with a diameter up to $100 \mathrm{~m}$ or more, rotating above the ground. In addition, there is extensive use of insulating composite materials, such as glass fibre reinforced plastic, as loadcarrying parts. The lightning protection system has to be fully integrated into the different parts of the wind turbines, ensuring that all parts likely to be lightning attachment points are able to withstand the impact of the lightning. Also, the lightning current should be conducted safely from the attachment points to the ground without unacceptable damage or disturbances to the systems. Wind turbines are excellent attachment points because they are often in exposed locations and significantly taller than adjacent objects. It is the blades that are by far the wind turbines most likely attachment points. However, almost any spot on the turbine is susceptible to direct lightning strikes including: air terminals, the nacelle, protuberances near the top of the structure, and the tower.

Although the increasing concern with wind turbine lightning protection is evident, there is no standard specifically written. The closest document is the technical report IEC/TR 61400-24 [5] which is purely informative, but it should be regarded as an important breakthrough. 
In January of 2006 a new four parts standard document has appeared (IEC 62305- 1 to 4) [6-9], providing the general principles of protection against lightning, risk management, protection measures against physical damages to structures and life hazard, and protection measures against damages to electrical and electronic systems within structures.

In order to perform the risk management proposed in [7] the CG lightning frequency per kilometre square and per year is needed. This parameter could be achieved with a network of appropriate sensors connected to a computer which is responsible to validate and record data events.

In Portugal the first Lightning Location System (LLS) is working since June of 2002 operated by the Institute of Meteorology (IM). In December of the same year Portugal began sharing its data with Spain. The system has now eighteen IMPACT sensors: four in Portugal and fourteen in Spain, of which Portugal share information with the nearest five.

This paper briefly describes the Portuguese Lightning Location System, and presents an overview of wind energy in Portugal. The method for risk assessment due to lightning flashes to earth, proposed by the International Electrotechnical Commission, IEC, is used. A wind power plant is characterized for a case study, and the standard IEC 62305-2 is applied. Results obtained are able to support the advantage for investors to take into account the lighting activity in the region where the wind power plant shall be installed. Also, the use of a well established risk assessment method allows the adoption of adequate protection measures.

\section{Lightning Location System}

The first LLS is working in Portugal since June 2002 and is operated by the IM. In December of the same year Portugal began sharing its data with Spain. The system has now eighteen IMPACT sensors: four in Portugal and fourteen in Spain, of which Portugal share information with the nearest five (Fig. 1).

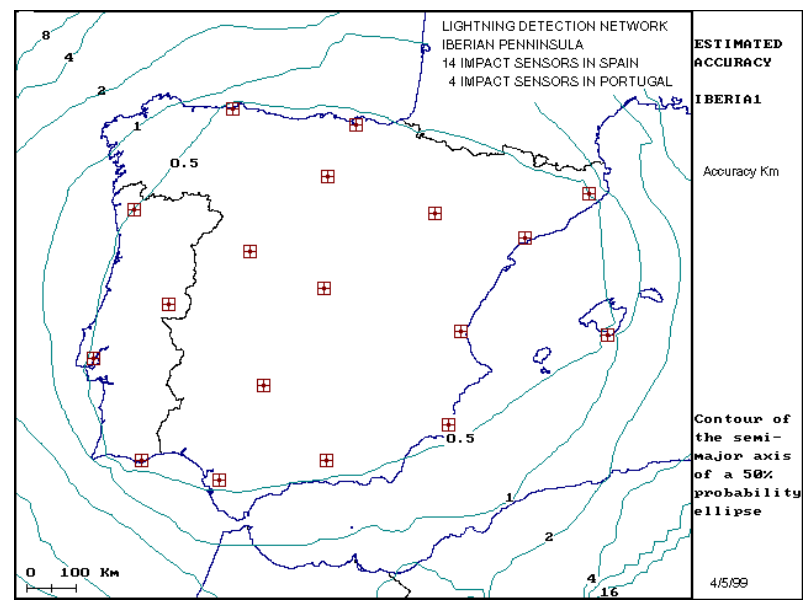

Fig. 1. Location and accuracy of the LLS operated by IM (source: IM)
Three methods are used to find the geographical location of lightning in latitude and longitude: magnetic direction, time-of-arrival, and a combination of the two. Furthermore, the system allows the measurement of the peak current and identifies the return stroke measured.

The software manufacturer announces an error in spatial location, over the continental area of Portugal, which is less than $500 \mathrm{~m}$ for the semi major axis of a $50 \%$ probability ellipse. The manufacturer also ensures efficiency higher than $90 \%$ for strokes with peak current greater than $5 \mathrm{kA}$, and for the same area (Fig. 2).

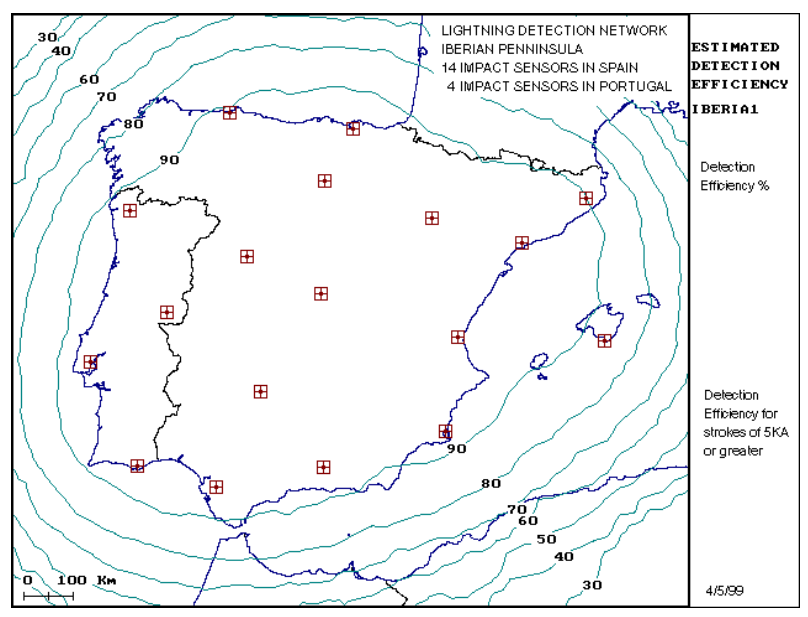

Fig. 2. Estimated detection efficiency of the LLS (source: IM)

The collected information after validation is recorded by the system in an ASCII file. This information is then analysed with database software resulting in probabilistic characterization.

More than half a million records were investigated to find out how many CG strikes occurred in the continental territory of Portugal. However, only nearly 200000 were considered as valid by the software. Figs. 3 and 4 show the number of positive and negative CG strikes between 2003 and 2006. In these figures the country was divided in squares with $100 \mathrm{~km}^{2}$. These were drawn taking into account only validated records.

Portugal has a percentage of positive CG strikes which is at least twice than what was expected, assuming the expected values coming from the employment of the IEC standards. The accumulative probability of peak current for Portugal shows smaller values when compared with the same curve given by IEC standards. According to the IEC curve, $80 \%$ of CG strikes have a peak current lower than $20 \mathrm{kA}$. However, for the Portuguese situation $80 \%$ of CG strikes have a peak current lower than about $10 \mathrm{kA}$. The number of CG strikes per kilometre square and per year, computed with the data illustrated in Figs. 3 and 4, is about 6 times lower than that given by thunderstorm day's map. Finally, the relative distribution of polarity by month shows a higher percentage of positive strikes in winter months, and a higher percentage of negative strikes in summer months. 


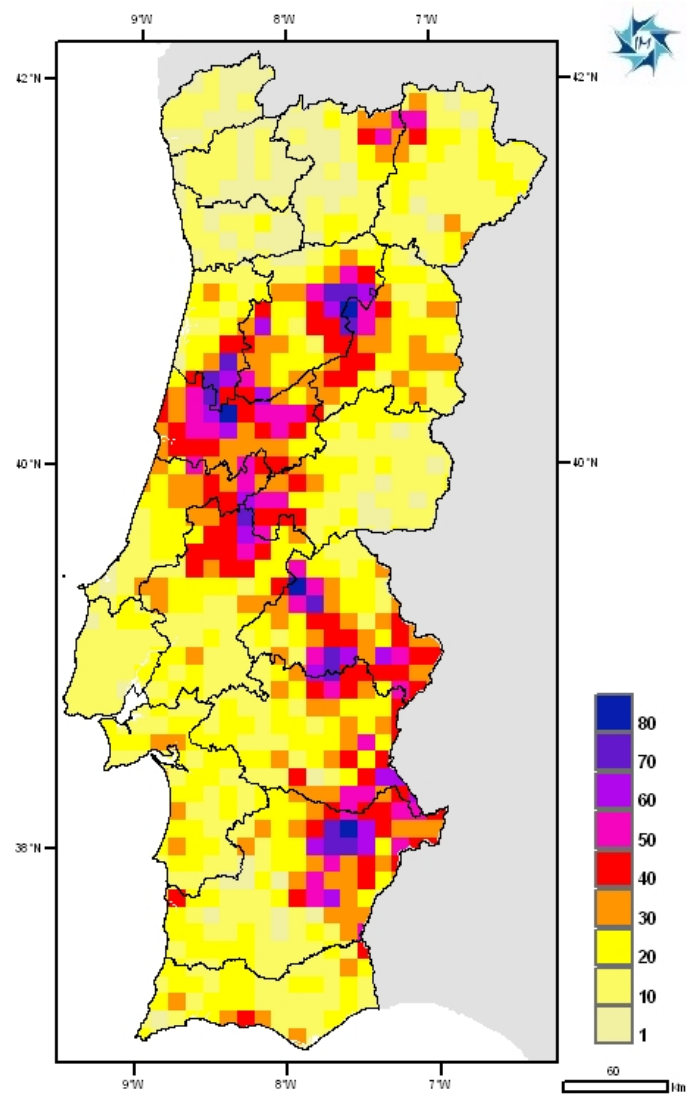

Fig. 3. Number of positive CG strikes between 2003 and 2006

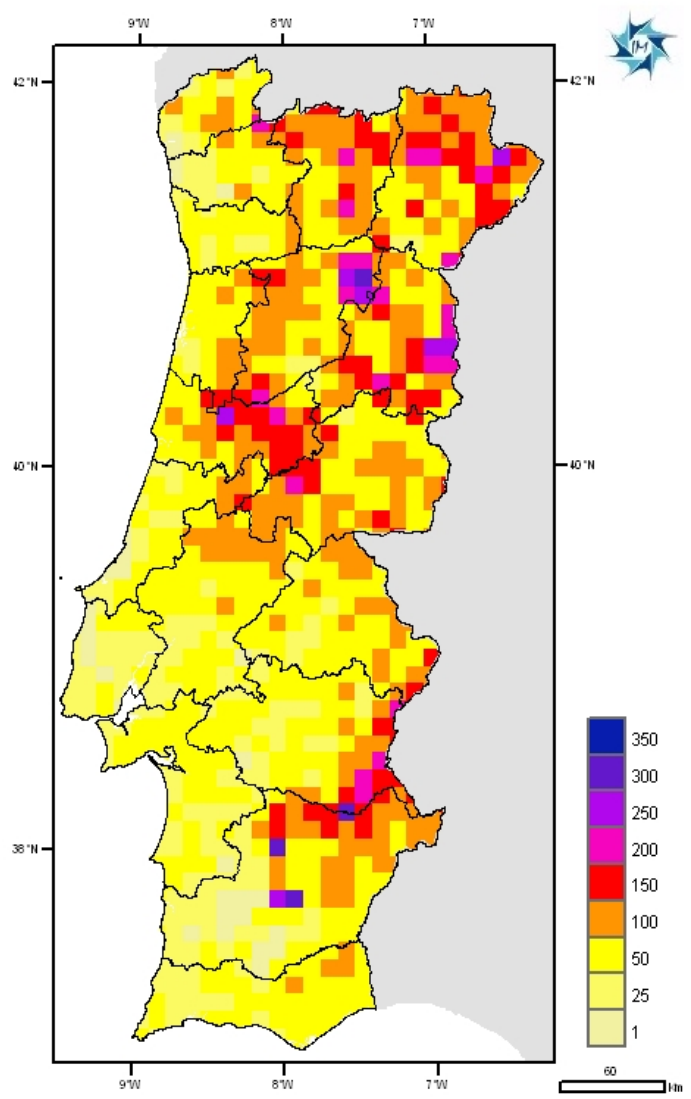

Fig. 4. Number of negative CG strikes between 2003 and 2006

\section{Wind Energy in Portugal}

The first wind turbine in Portugal was installed at Lourel, in 1985. This wind turbine was an Aeroman 12/20 model with $20 \mathrm{~kW}$. A few more wind turbines were connected to the electrical grid during the next thirteen years. Since 1998 the wind power capacity increased considerably, as shown in Fig. 5.

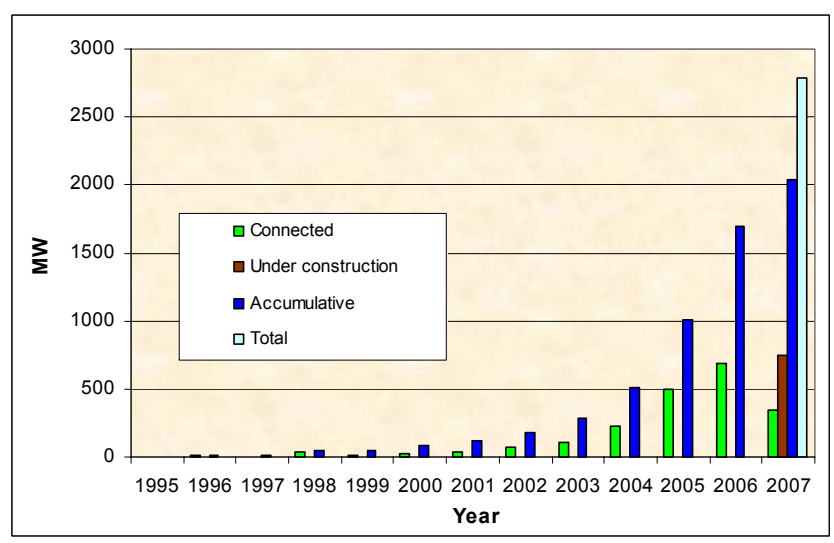

Fig. 5. Wind power in Portugal, from 1995 to 2007

The overall situation of wind power in mainland Portugal until September 2007 is observed in Fig. 6 and in Table I.

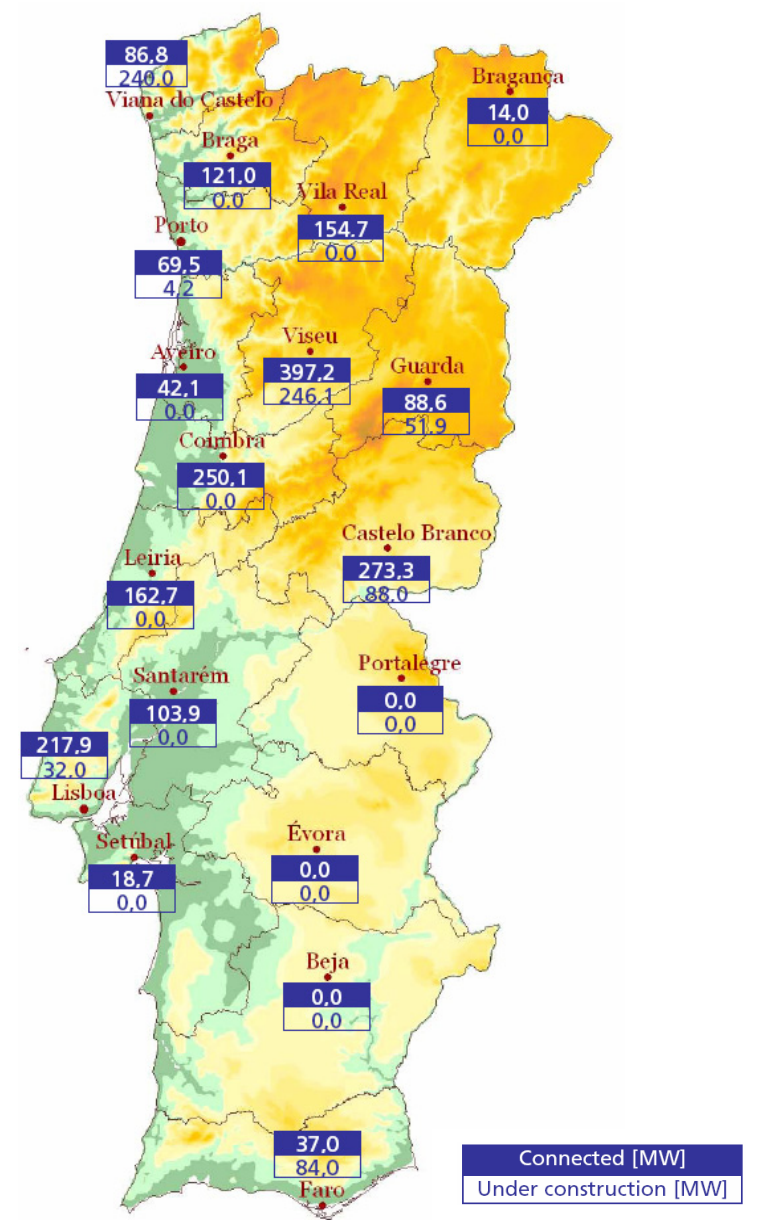

Fig. 6. Wind power capacity in mainland Portugal by district 
TABLE I. - General data of wind power in mainland Portugal

\begin{tabular}{|c|c|}
\hline $\begin{array}{c}\text { Estimated sustainable wind potential onshore } \\
(\mathrm{MW})\end{array}$ & 4800 \\
\hline $\begin{array}{c}\text { Total capacity in operation in September } 2007 \\
(\mathrm{MW})\end{array}$ & 2037 \\
\hline $\begin{array}{c}\text { Total capacity under construction in September } 2007 \\
(\mathrm{MW})\end{array}$ & 746 \\
\hline
\end{tabular}

As higher is the number of wind turbines in operation, the higher is the risk of unplanned downtime due to lightning. Hence, Portugal requires more attention in what regards lightning protection for the wind power plants.

\section{Method for Risk Assessment due to Lightning Flashes to Earth}

The method used in this paper for risk assessment on a structure or on a service due to lightning flashes to earth is based on IEC 62305 part 2 [7]. The scope of this part of IEC 62305 is to provide a procedure for the evaluation of such a risk. Once an upper tolerable limit for the risk has been ascertained, this procedure allows the selection of appropriate protection measures, in order to reduce the risk at or below the tolerable limit. The following should be intended as a minimal report set in order to explain such a method.

Lightning flashes influencing a structure or a service are considered sources of damage and are divided into:

- $\quad$ S1 - flashes striking the structure;

- S2 - flashes striking near the structure and/or near the connected services (power, telecom lines, other services);

- $\quad \mathrm{S} 3$ - flashes striking the service;

- S4 - flashes striking near the service or direct to a structure connected to the service.

Lightning flashes can be hazardous to life, to structures and to services and the following damages are considered:

- D1 - injuries of living beings in or close to the structure;

- D2 - damages to the structure and to its contents;

- D3 - failures of associated electrical and electronic systems.

Source of damage S1 and S3 may cause damages of type D1, D2 and D3. Source of damage S2 and S4 may cause damages of type D3. Moreover, failures caused by lightning overvoltages in users' installations and in power supply lines may also generate switching type overvoltages in the installations.

Effects of the damages and failures may not only involve its environment, but also extended to the surroundings of the structure. Each type of damage, alone or in combination with others, may produce a different consequent loss in the object to be protected. The type of loss that may appear depends on the characteristics of the structure itself and its content. The following types of losses shall be taken into account:

- L1 - Loss of human life;

- L2 - Loss of service to the public;

- L3 - Loss of cultural heritage;

- L4 - Loss of economic value (structure and its content, service and loss of activity).

Protection measures may be required to reduce the loss due to lightning. Whether they are needed and to what extend should be determined by risk assessment. The risk, defined in [7] as the average annual loss on a structure or on a service due to lightning flashes to earth, depends on:

- the annual number of lightning flashes influencing the structure and/or the service;

- the probability of damage by one of the influencing lightning flashes;

- the average amount of the consequent loss.

The number of lightning flashes influencing the structure or the service depends on their: dimensions and characteristics; environment characteristics; as well as on lightning ground flash density $N g$ in the region. The probability of lightning damages depends on the structure, the service and the lightning current characteristics, as well as on the kind and efficiency of applied protection measures. The annual average amount of the consequential loss depends on the extent of damages and the consequential effects, which may occur as result of a lightning flash. The effects of protective measures result from the features of each protection measure and allows for a reduction of the damage probability and the amount of consequential loss.

The mathematical expression used on [7] to assess the risk value is based on:

$$
R=\left(1-e^{-N P t}\right) L
$$

where $N$ is the number of lightning flashes influencing the structure and/or the service; $P$ is the probability of damage by one of the influencing lightning flashes; $L$ is the consequent mean amount of loss; and $t$ is the period under evaluation, which is usually considered one year. As the product $N P t$ is $N P t<<1$, Equation (1) becomes

$$
R=N P L t
$$

The risk $R$ is the measure of a loss. For each type of loss, $\mathrm{L} 1$ to $\mathrm{L} 4$, the relevant risk shall be evaluated. The risks to be evaluated in a structure may be:

- R1 - Risk of loss of human life;

- R2 - Risk of loss of service to the public;

- R3 - Risk of loss of cultural heritage;

- R4 - Risk of loss of economic value.

The risks to be evaluated in a service may be:

- R'1 - Risk of loss of human life;

- R'2 - Risk of loss of service to the public;

- R'4 - Risk of loss of economic value.

To evaluate $R$ the relevant risk components (partial risks depending on the source and on the type of damage) shall 
be defined and calculated. $R$ is the sum of its risk components which may be grouped according to the source of damage and the type of damage.

It is the responsibility of the national authority having jurisdiction to identify the value of tolerable risk $R_{T}$. Representative values of $R_{T}$, where lightning flashes involve loss of human life or loss of social or cultural values, are reported in Table II. For more details on the background of these values reference can be made to BS 6651-1985 and to publications relevant to fatal accident rate.

TABLE II. - Typical values of tolerable risk $R_{T}$

\begin{tabular}{|l|l|}
\hline Loss of human life & $10^{-5}$ \\
\hline Loss of service to the public & $10^{-3}$ \\
\hline Loss of cultural heritage & $10^{-3}$ \\
\hline
\end{tabular}

The procedure to evaluate the need of protection shall consider the following steps:

- identification of the components $R_{i}$ which make up the risk;

- calculation of the identified risk components $R_{i}$;

- calculation of the total risk $R$;

- identification of the tolerable risk $R_{T}$;

- comparison of the risk $R$ with $R_{T}$.

If $R \leq R_{T}$ lightning protection is not necessary. If $R>R_{T}$ protection measures shall be adopted in order to reduce $R$ until $R \leq R_{T}$ for all risks considered.

The method proposed in [7], for risk assessment due to lightning flashes to earth, requires a great number of input data and computation. To overcome these difficulties, the LPS 2008 computer program has been used. Some advantages of LPS 2008 are: completely adapted to the new IEC standard (IEC 62305), which is used for risk assessment; allowing the risk analysis with BS 6651 and IEC 61662; running over any version of AutoCAD (since AutoCAD 2000), making easier to model 3D structures (like buildings, telecom antennas, wind turbines, etc.); performing the rolling sphere method (RSM) simulation, which marks all vulnerable points on a structure, or set of structures, for the selected protection level according to [7].

\section{Characterization of the Case Study}

The wind power plant under study has 25 wind turbines with $2 \mathrm{MW}$ of rated power. Rotor blades are manufactured using the so-called sandwich method. Glass fibre mats placed in the mould are vacuumimpregnated with resin via a pump and a hose system. The rotor diameter is about $82 \mathrm{~m}$. The rotor hub and annular generator are directly connected to each other as a fixed unit without gears. The rotor unit is mounted on a fixed axle. The drive system has only two slow-moving roller bearings due to the low speed of the direct drive. The annular generator is a low-speed synchronous generator with no direct grid coupling. Hence, the output voltage and frequency varies with the speed, implying the need for a converter via a DC link in order to make a connection to the electric grid. The hub height varies between 70 to $138 \mathrm{~m}$. The tubular steel towers are manufactured in several individual tower sections connected using stress reducing L-flanges. The LV/HV transformer is placed at the bottom of the tower. It has $2500 \mathrm{kVA}$ of rated power and has a special design to fit the reduced dimensions and working conditions of the tower. In Fig. 7 a wind turbine is represented. The wind turbines were modelled in 3D with AutoCAD.

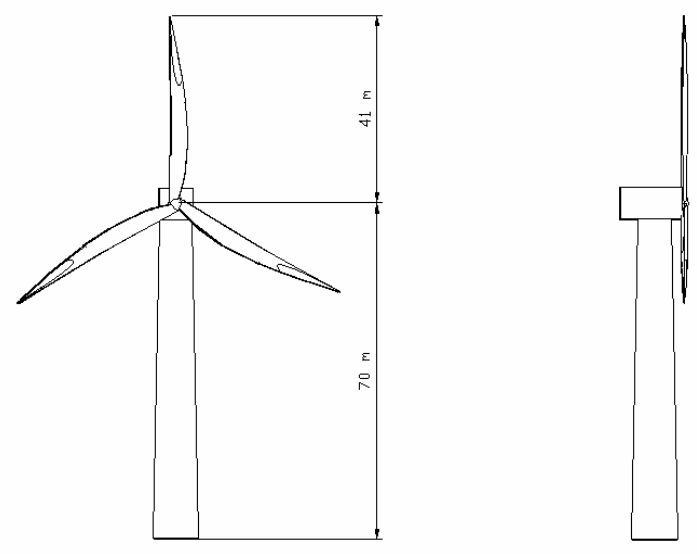

Fig. 7. 3D model and dimensions of a wind turbine

Ensuring proper power feed from wind turbines into the grid requires grid connection monitoring, shown in Fig. 8.

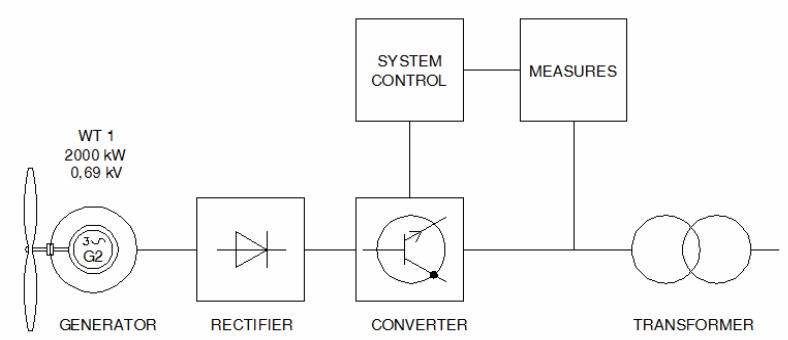

Fig. 8. Grid connection monitoring on wind turbines

The 25 wind turbines are arranged in groups of 5 with distance among towers around $350 \mathrm{~m}$. Fig. 9 shows the electric schema of a LV/HV substation near the tower.

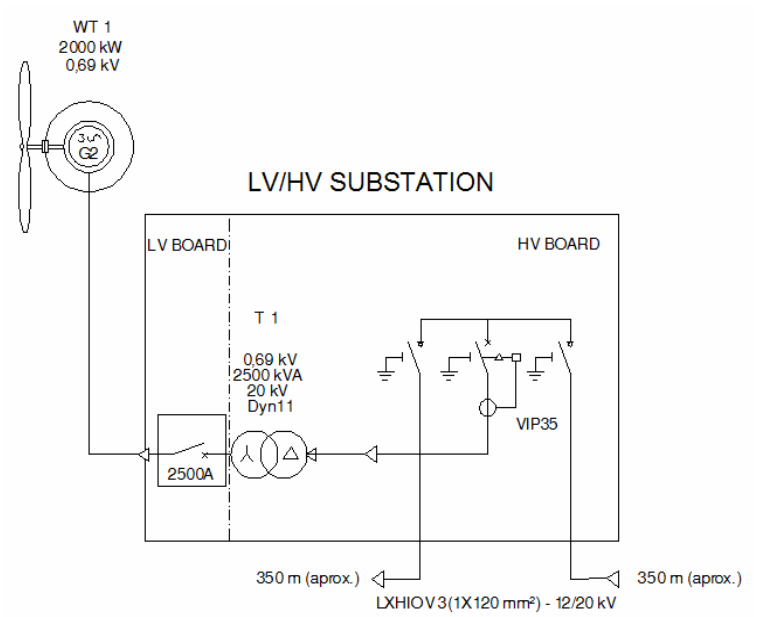

Fig. 9. LV/HV substation near the tower 
Cables connecting these groups enter in the main substation, which has an external part, Z1, and an internal part, Z2, as shown in Fig. 10. Also, this figure shows the collection area $\left(A_{d}\right)$ for flashes to an isolated structure [7].

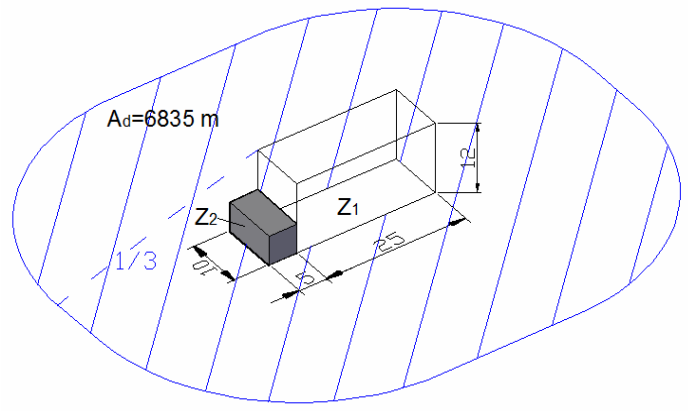

Fig. 10. Main substation at wind power plant

\section{Results}

Results show a risk value $R$ higher than tolerable risk $R_{T}$ for L1 - Loss of human life and for L2 - Loss of service to the public (see Table II). In order to reduce the value of $R$ the main substation must be protected with a Class I lightning protection system (LPS), and surge protective devices (SPD) must be installed. Fig. 9 shows the result of RSM simulation, applied to a wind turbine, done by LPS 2008. Fig. 10 shows the electric schema of the external part main substation with SPD installed.

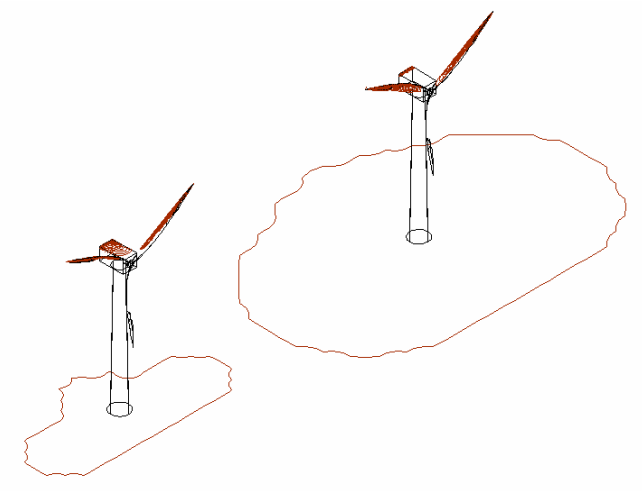

Fig. 9. Result of RSM simulation with LPS 2008 for protection level I (efficiency of 98\%) and IV (efficiency of $80 \%$ )

\section{Conclusion}

This paper presents a brief characterization of the Portuguese LLS. Based on data from LLS, the lightning activity over Portugal is presented and discussed. An overview of wind energy in Portugal in what regards: the installed capacity; the capacity under construction; and the geographical location, is also presented. The method for risk assessment due to lightning flashes to earth, proposed by IEC, is presented. As a case study, a wind power plant is characterized and the standard IEC 62305-2 is applied. Results attained are in favour of supporting technical and economical decisions able for taking into account the lighting activity in the region where the wind power plant is installed. Also, the use of a well established risk assessment method allows the adoption of adequate protection measures.

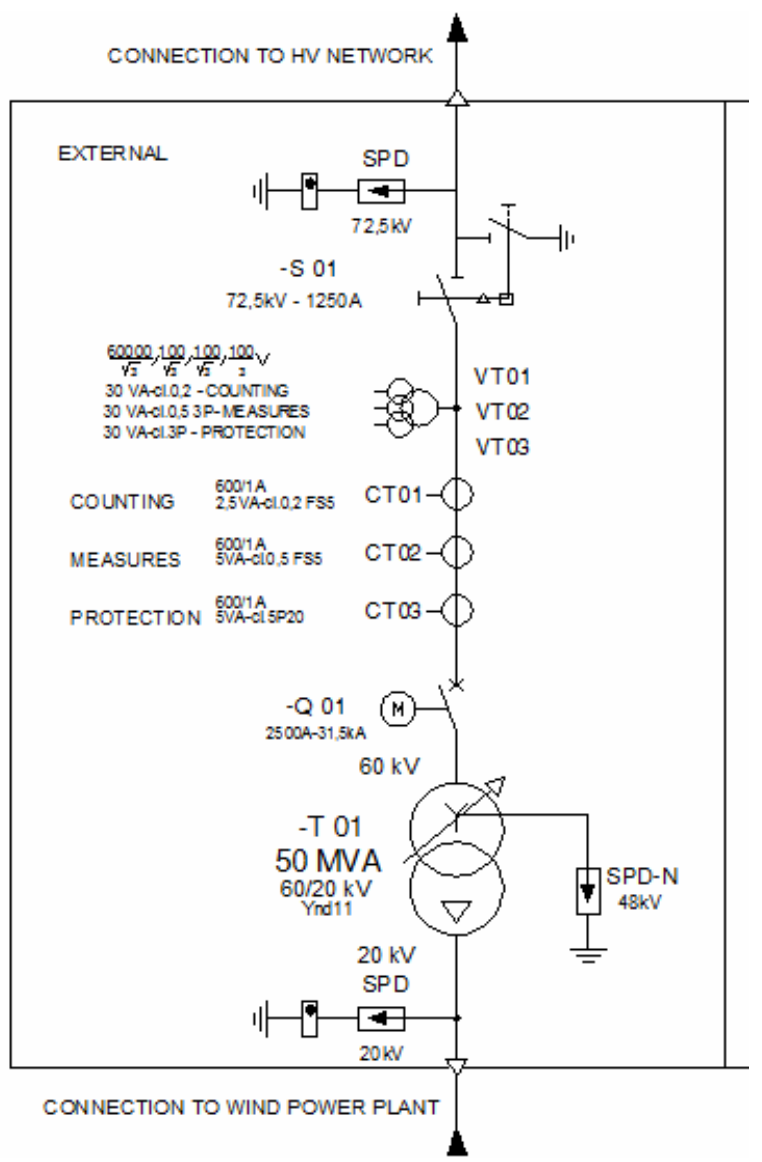

Fig. 10. Electric schema of the external part main substation with SPD installed

\section{References}

[1] M. Paolone et al., "Models of wind-turbine main shaft bearings for the development of specific lightning protection systems", IEEE Power Tech Proceedings, July 2007.

[2] National Renewable Energy Laboratory statistics, www.nrel.gov, 2002.

[3] M. Durstewitz et al., "External conditions for wind turbine operation - Results from the German 250 MW programme", Euro Union Wind Energy Conference, May 1996.

[4] B. Glushakow, "Effective lightning protection for wind turbine generators", IEEE Trans. On Energy Conversion, Vol. 22, No. 1, pp 214-222, March 2007

[5] TR 61400-24. Ed. 1: "Wind turbine generator systems - Part 24: Lightning protection", International Electrotechnical Commission, July 2002.

[6] IEC 62305-1. Ed. 1: "Protection against lightning Part 1: General principles", January 2006.

[7] IEC 62305-2, Ed.1: "Protection against lightning Part 2: Risk management”, January 2006.

[8] IEC 62305-3, Ed.1: "Protection against lightning Part 3: Physical damages to structures and life hazard", January 2006.

[9] IEC 62305-4, Ed.1: "Protection against lightning Part 4: Electrical and electronic systems within structures", January 2006. 